\title{
УПРАВ/ЕНИЕ МОДЕРНИЗАШИЕЙ
}

\author{
А. С. Королев
}

\section{РАЗВИТИЕ АВИАЦИОННОЙ ОТРАСЛИ ИНДИИ НА СОВРЕМЕННОМ ЭТАПЕ}

\begin{abstract}
Аннотация. Предметом исследования является авиационная отрасль Индии. В данной статье рассмотрены национальные стратегические планы и государственные инициативы в авиационной сфере (Стратегический план Министерства гражданской авиации Индии на 2010-2015 г2. и Стратегия развития «Индия: Видение 2020»). Кроме того, проанализированы инвестиционные программы Индии по развитию авиахабов на своей территории. Будучи четвертой экономикой мира и второй страной по численности населения, Индия рано или поздно должна была стать и важным сегментом рынка авиаперевозок. Основным методом исследования является статистический анализ. В рамках исследования проведен SWOT-анализ. Он основан на результатах таких показателей, как: прирост ВВП, рост среднего класса, рост совокупных доходов населения, динамика прироста грузооборота индийских аэропортов. Новизна исследования заключается в комплексном анализе индийской авиационной промышленности на современном этапе. Проведен SWOT-анализ, позволяющий выявить сильные и слабые стороны данной отрасли, оценить риски, с которыми сталкивается авиационная индустрия Индии и дать рекомендации по ее развитию. Основными выводами проведенного исследования являются: авиационная отрасль Индии обладает большим потенциалом за счет динамичного роста среднего класса, повышения располагаемых доходов, государственной поддержки, растущих прямых иностранных инвестиций, использования передовых информационных технологий, в т. ч. - собственного производства. Помимо внутренних ресурсов, авиационная индустрия Индии обладает значительным потенциалом с точки зрения использования возможностей международного сотрудничества: и как члена БРИКС, и особенно как страны, чей представитель - Президент Нового банка развития БРИКС, и как члена ШОС с 2015 г., и как все более активного игрока на азиатских диалоговых площадках. Учитывая все эти факторы, в долгосрочной перспективе Индия может войти в число ведущих игроков на мировом рынке авиаци.
\end{abstract}

Ключевые слова: Индия, авиационная отрасль, аэропорты, инфраструктура, БРИКС, Открытое небо, ШОС, Средний класс, Государственно-частное партнерство, численность населения.

Abstract. Being the fourth economy in the world and the second most-populous country, India, sooner or later should have become an important segment of the air transport market. Indian aviation industry has great potential due to the dynamic growth of the middle class, increasing disposable personal income, state support, rising foreign direct investment. In addition to internal resources, the aviation industry in India has great potential in terms of the opportunities for international cooperation, both as a member of BRICS, especially as a country whose representative - the President of the New Development Bank BRICS and as an active participant of the Asian dialogue platforms. India is a leader of South Asia, where Open Skies Agreement is in force, which allows international airlines to carry out operations in the airspace of the signatory powers. The synergetic effect of cooperation with developing countries (China, Russia, and Brazil) will contribute to the gradual resolution of the fundamental problems which Indian aviation industry faces nowadays (overcapacity, high level of debt loads, liquidity shortage), and as a result - to strengthening of the competitiveness of the sector at the global level. Considering all these factors, in the long run India can become one of the leading players in the global aviation market.

Keywords: Population, State-private partnership, Middle class, SCO, Open skies, BRICS, Infrastructure, Airports, Aircraft industry, India. 


\section{Тренды и управление 2(14) • 2016}

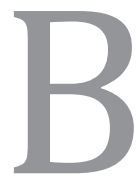

настоящее время Индия является 9-м по величине (пассажиропоток + грузооборот) мировым авиационным рынком с 85 международными авиалиниями, соединяющими более 40 стран. Размер индийского рынка составляет 16 млрд. долларов и к 2020 г. Индия намерена закрепиться на третьем месте, а к 2030 г. - стать мировым лидером.

По оптимистичным оценкам, средний класс Индии на данный момент насчитывает скромные 50 млн. человек. Но к 2025 г. данный показатель может составить 583 млн., около 41\% населения, а в 2040 г. - уже более $80 \%$ населения будут представлять средний класс [1]. Совокупные доходы населения могут вырасти в 4 раза и к 2025 г. и составить более 1 трлн. долл. США. ности, что вынуждает большинство индийских авиаперевозчиков осуществлять значительные прямые финансовые вливания в развитие авиационной индустрии.

По-прежнему многие крупные аэропорты страны испытывают острую нехватку средств складского хранения для воздушных перевозок, что негативно отражается на обслуживании грузовых поставок внутри страны. Однако власти страны осознают эту проблему, и предлагают комплексный подход к ее решению.

Передача технологий и привлечение прямых иностранных инвестиций является важнейшим инструментом развития авиационной отрасли. Однако в Индии этот процесс осложняется отсутствием механизмов адаптации

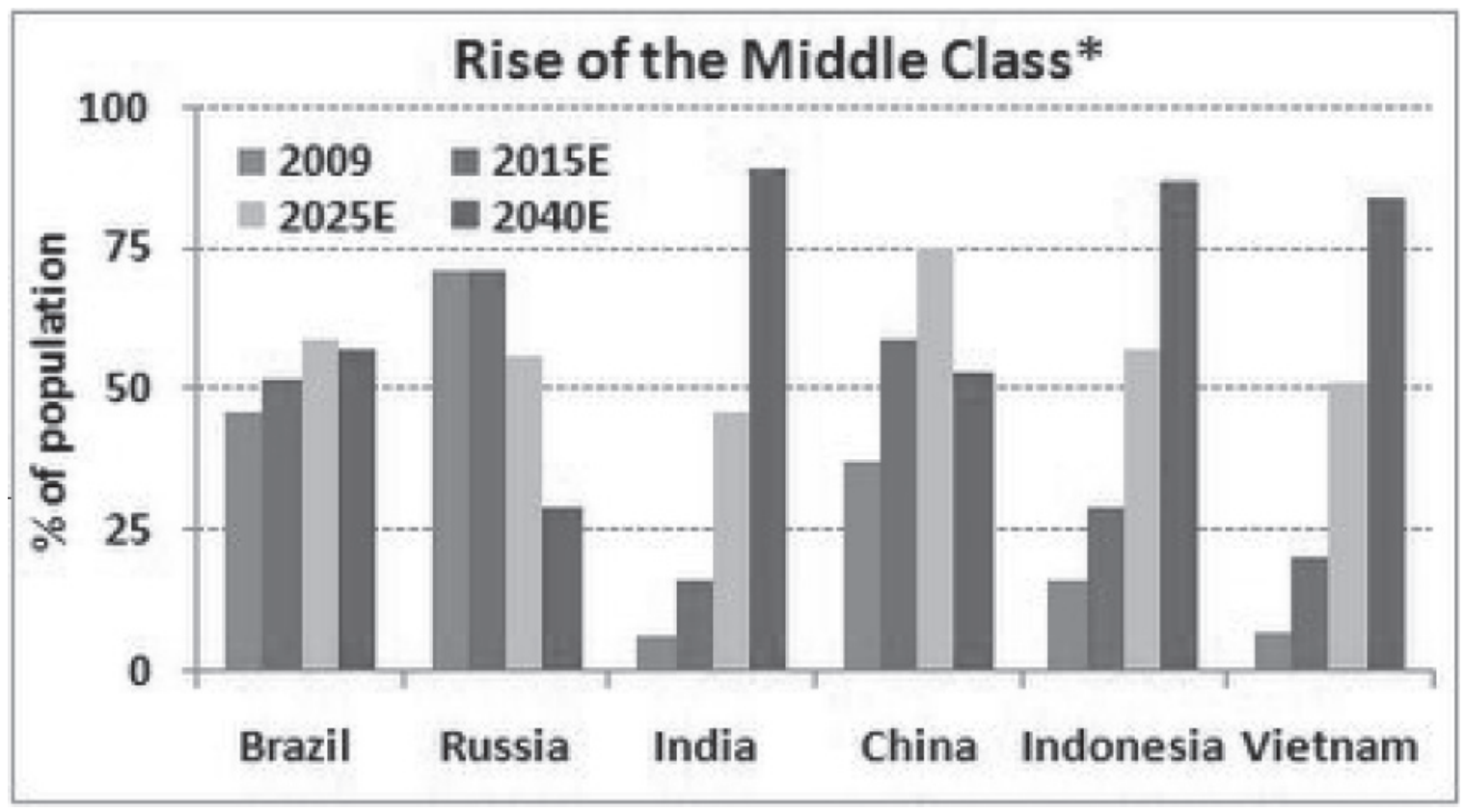

Рис. 1. Рост среднего класса в Индии

Источник - McKinsey Global Institute

\section{Проблемы индийской авиаотрасли}

Несмотря на успехи в последние годы, авиационная отрасль Индии по-прежнему сталкивается с рядом проблем. Среди них можно выделить излишек производственных мощностей, высокий уровень долговой нагрузки и дефицит ликвид- новых технологий на национальном уровне. Проблема адаптации новых технологий также обусловлена низкой степенью вовлеченности индийских бизнес-структур в развитии и внедрении высоких технологий в авиационной промышленности. 


\section{Управление модернизацией}

\section{Государственные инициативы в авиационной сфере}

Основными документами, описывающие практические меры по развитию авиационной отрасли Индии в краткосрочной и среднесрочной перспективе, являются: Стратегический план Министерства гражданской авиации Индии на 2010-2015 гг. и Стратегия развития «Индия: Видение 2020».

Ключевые целевые показатели, зафиксированные в этих документах, весьма амбициозны: общий объем инвестиций в авиационный сектор в период между 2004 и 2020 гг. достигнет 120 млрд. долл. США, из которых 80 млрд. долл. будет выделено на покупку новых самолетов, 30 млрд. долл. - на развитие инфраструктуры аэропортов, 10 млрд. долл. - на дополнительные услуги, такие как наземное обслуживание, техническое обслуживание, управление воздушным движением, обеспечение безопасности и подготовку кадров [2]. Впрочем, ПИИ в воздушный транспорт Индии (включая авиаперевозки) в период с апреля 2000 г. по май 2015 г. составил 573 млн. долларов [3]. Однако уже в августе 2015 г. индийский премьер выделил 414 млн. долл. на развитие четырех новых аэропортов в одном из наиболее бедных штатов страны - Бихар [4].

Стратегический план сконцентрирован вокруг следующих направлений: создание инфраструктуры мирового уровня, создание нормативно-правовой базы в соответствии с международными стандартами, подготовка и привлечение квалифицированной рабочей силы исходя из потребностей отрасли.

Документ включает в себя меры по интенсификации взаимодействия государства с частным сектором в целях минимизации рисков и преодоления препятствий, стоящих на пути модернизации авиационного сектора и решения вопросов налогообложения, пошлин и других экономических ограничений, оказывающих негативное влияние на развитие отрасли.

Несмотря на широкий охват стратегического плана, в нем не были прописаны конкретные механизмы достижения поставленных задач, что не позволяет в полной мере оценить итоги реализации. Так или иначе, процесс интенсификации данного вида сотрудничества сопряжен с рядом проблем, от оперативного решения которых во многом зависят дальнейшие перспективы авиационной отрасли. Среди них: отсутствие мощных каналов коммуникации по линии государственно-частного партнерства (ГЧП) и небольшой опыт работы органов власти в авиационной сфере.

Согласно Стратегии развития «Индия: Видение $2020 »$, к 2020 г. правительство Индии планирует:

- построить дополнительно 200 аэропортов, придав импульс экономическому подъему северо-востока страны;

- увеличить объем авиационного парка до 1,030 единиц;

- увеличить общий объем пассажиропотока до 450 млн. человек;

- увеличить объем грузооборота индийских аэропортов до 6,2 млн. тонн;

- сформировать комитет, состоящий из банков, специалистов в области авиации и современных технологий для ускорения процесса приватизации национального авиаперевозчика Air India.

Кроме того, политические круги Индии намерены разработать «дорожную карту» для ускоренного развития авиационного сектора, в которой будет отражена инициатива нынешнего премьера расширить сеть ГЧП, сделав их основой модернизации инфраструктуры.

С точки зрения использования возможностей международного сотрудничества, у Индии довольно широкие перспективы: и как члена БРИКС, чей представитель - Президент Нового банка развития БРИКС, и как члена ШОС с 2015 г., и как все более активного игрока на азиатских диалоговых площадках. Индия - лидер Южной Азии, где действует Соглашение об открытом небе. В то же время Индия не имеет налаженных механизмов сотрудничества уровня ACEAH+3, пока не предлагает собственных институтов развития как Китай и на данном этапе только входит в роль «полуконтинентальной» державы. 


\section{Тренды и управление 2(14) • 2016}

\section{SWOT - анализ по Индии}

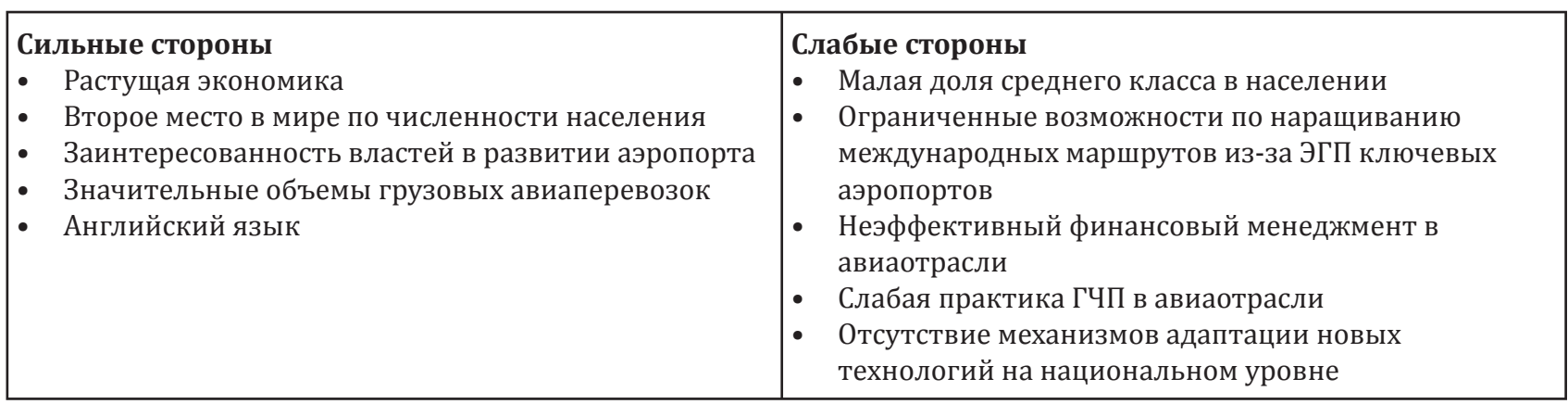

\section{Возможности}

- Увеличение численности и доли среднего класса в населении

- Ввод режима «открытого неба» для отдельных городов, подключение к соглашениям об открытом небе стран ЮВА.

- Популяризация систем e-cargo, e-freight и пр.

\section{Угрозы}

- Негативное влияние мировой экономической конъюнктуры

- Конкуренция со стороны других азиатских стран

- Аутсорсинг производства в Индии может замедлить процесс индустриализации в авиационной промышленности

\section{Рекомендации}

Во-первых, перспективным направлением в целях повышения конкурентоспособности индийской авиаотрасли на глобальном уровне является укрепление взаимодействия со странами БРИКС. Создание институциональной основы многостороннего сотрудничества, предполагаюеее активный обмен опытом, знаниями и ресурсами, поспособствовало бы постепенному решению проблем, с которыми сталкивается индийская авиация, и как итог - укреплению позиций на мировом авиационном рынке. Наличие тесного политического диалога между странами послужит практическим инструментом реализации данного вида сотрудничества.

Во-вторых, необходимо существенно увеличить объем государственной поддержки научноисследовательских и опытно-конструкторских работ (НИОКР), чтобы заложить научную и технологическую основу (технологии + компетенции) для производства новых коммерческих продуктов.

В-третьих, развитие авиационной отрасли подразумевает тесное сотрудничество между бизнесом и государством. В связи с этим целесообразным является расширение сферы деятельности ГЧП с целью коммерциализации авиационной промышленности.

Важно отметить, что будущее авиационной отрасли Индии будет напрямую зависеть от уровня инфраструктурного развития, внедрения и повсеместного использования современных технологий, разработка которых требует дополнительной материальной и институциональной поддержки. В этом направлении государственное участие (реализация федеральных программ, предоставление субсидий и иных льгот) станет катализатором модернизации данной отрасли.

Наконец, кооперация авиационной промышленности с другими смежными отраслями, в которых широко задействована высокотехнологичная продукция, ускорит модернизацию авиационной индустрии Индии. Развитие данной отрасли, в свою очередь, поспособствует увеличению положительных эффектов для экономики страны, прежде всего, промышленного производства.

Совокупность всех факторов позволяет прийти к выводу, что в течение следующего десятилетия, Индия, несомненно, имеет возможность стать важной частью глобального рынка авиации. 


\section{Управление модернизацией}

\section{Библиография}

1. Asia One. India's ghost airports highlight risks as Modi spends to grow. - URL: http://news.asiaone. com/news/asia/indias-ghost-airports-highlight-risks-modi-spends-grow

2. Centre for Asia Pacific Aviation. Preparing for Long Term Growth of Indian Aviation. URL: http://www. atcguild.com/members/Sem10/presentations/Kaul-ppt.pdf

3. India Brand Equity Foundation. Indian Aviation Industry. URL: http://www.ibef.org/industry/indianaviation.aspx

4. McKinsey Global Institute. Next big spenders: India's middle class. URL: http://www.mckinsey. com/Insights/MGI/In_the_news/Next_big_spenders_Indian_middle_class

5. Спиридонов В.В. К вопросу о создании Банка развития БРИКС: перспективы, потенциал, преимущества // Конфликтология / nota bene. - 2014. - 1. - C. 109 - 121. DOI: 10.7256/.2014.1.12892.

6. А. Г. Коряков Роль государства в обеспечении устойчивогоразвития отраслей экономики // Национальная безопасность / nota bene. - 2012. - 4. - С. 4 - 12.

\section{References (transliterated)}

1. Asia One. India's ghost airports highlight risks as Modi spends to grow. - URL: http://news.asiaone. com/news/asia/indias-ghost-airports-highlight-risks-modi-spends-grow

2. Centre for Asia Pacific Aviation. Preparing for Long Term Growth of Indian Aviation. URL: http://www. atcguild.com/members/Sem10/presentations/Kaul-ppt.pdf

3. India Brand Equity Foundation. Indian Aviation Industry. URL: http://www.ibef.org/industry/indianaviation.aspx

4. McKinsey Global Institute. Next big spenders: India's middle class. URL: http://www.mckinsey. com/Insights/MGI/In_the_news/Next_big_spenders_Indian_middle_class

5. Spiridonov V.V. K voprosu o sozdanii Banka razvitiya BRIKS: perspektivy, potentsial, preimushchestva // Konfliktologiya / nota bene. - 2014. - 1. - C. 109 - 121. DOI: 10.7256/.2014.1.12892.

6. A. G. Koryakov Rol' gosudarstva v obespechenii ustoichivogorazvitiya otraslei ekonomiki // Natsional'naya bezopasnost' / nota bene. - 2012. - 4. - C. 4 - 12. 